\title{
A Direct Application of Simultaneous Interpreting Training without Prior Consecutive Interpreting Work in a University Course
}

\author{
Hiroko Yamada \\ Kansaigaidai College, Osaka, Japan
}

\begin{abstract}
There is a general consensus that novice interpreters should begin their training with consecutive interpreting (CI) and only move on to simultaneous interpreting (SI) after they have mastered CI. However, working memory (WM) capacity plays a central role in developing professional SI skills, and may even be more important than extended practice. As there is great variability in the innate cognitive abilities of individual people, some novice interpreters may have the potential to perform SI reasonably well. The present study has tested this hypothesis by offering SI training to novice interpreters in a university course, without administering prior CI training during the semester. Midterm and final examinations were conducted to analyze the learners' SI performances. The findings suggest that student interpreters can perform SI quite well, subject to certain conditions such as preparation time, input rates, and source-text intelligibility. This study explores the pedagogical implications of introducing student interpreters directly to SI training, as well as the curricular arrangements involved.
\end{abstract}

Index Terms - new learners, simultaneous interpreting, direct application, university, preparation

\section{INTRODUCTION}

The International Association of Conference Interpreters (AIIC) defines simultaneous interpreting (SI) as follows: "In a sound-proof booth with [a] direct view onto the conference room, the interpreter listens to a speaker through earphones and simultaneously transmits the message in another language through a microphone to listeners in the room." From a technical point of view, the simultaneous interpreter must continuously monitor, store, retrieve, and decode input in the source language, while simultaneously recoding and encoding a translation of the input (Goldman-Eisler, 2002).

In recent years, the development of expertise in SI has drawn the attention of researchers studying cognitive processes and teachers exploring the cognitive models that have shaped the teaching of interpretation. Most cognitive process models of SI envisage a short-term storage function. SI skills are assumed to be related to working memory (WM) capacity (Pöchhacker, 2016). However, some studies regarding the relationship between WM capacity and performance levels in SI have yielded mixed results. Liu et al. (2004) found no significant difference between the WM capacity of student interpreters and professionals, suggesting that SI experience does not guarantee enhanced working memory. Köpke and Nespoulous (2006) have argued that WM is highly variable, depending more on an individual's innate cognitive abilities than on time spent in extended practice of a professional skill. Recent studies have produced inconclusive findings as to whether professional simultaneous interpreters have higher WM capacities than trainee interpreters or non-interpreting bilinguals (Köpke and Signorelli, 2012; Padilla et al., 1995; Seeber, 2015). There is a significant difference in the SI capacity of experienced interpreters and trainees who have no experience, when it comes to processing issues, including lexical access, target-language delays, equivalence, and the source-language input rate (Tiselius and Jenset, 2011). This suggests that the degree of experience influences the processing strategies used by interpreters and the types of problems they encounter.

Turning to the pedagogical implications, it is generally accepted that trainee interpreters should begin with the consecutive mode, based on memory and note-taking, before gradually moving on to simultaneous interpreting (Selescovitch \& Lederer, 1989; Pöchhacker, 2016). In most major university-associated interpreting schools in the West, programs last two to four years (generally two years at the graduate level and three or four years at the undergraduate level). Students receive CI training prior to SI training (Gile, 2009; Ito, 2017). One basic tenet of the Paris School approach is that students must demonstrate considerable mastery over CI before progressing to SI training (Pöchhacker, 2016). In Japan, however, where most teachers are practicing interpreters and few had prior teaching experience, teachers have begun to discuss the "best approach and method" for teaching conference interpreting (Komatsu, 2017). There are different schools of thought on how and when to start teaching SI (Komatsu, 2017). 
The present study argues that untrained student interpreters who receive a fair amount of direct SI training under optimal conditions may develop SI comprehension and production skills, producing acceptable SI target texts, even if they have not undertaken any prior CI activities. To test this hypothesis, this study has examined the effect of direct SI training on 20 students in an English-to-Japanese introductory university interpreting course during the 2018 spring semester. The course consisted of consecutive three-hour lessons in L2 (English)-to-L1 (Japanese) SI training, including SI-related tasks such as shadowing, sight translation, and semantic chunking input (listening in a translation unit). The students attended one three-hour lesson (two 90-minute lessons combined) once a week, completing a total of 15 lessons (45 hours) during the semester. Their SI skills were assessed through midterm and final examinations.

It is possible that students undergoing SI training may develop better listening comprehension skills because they come to understand L2 speech segments lineally, in the order they hear them in, without being distracted by syntactic differences between L2 and L1 or other language-specific problems. To test this theory, participants took TOEIC listening tests at the beginning and end of the semester.

The present study began by examining the effect of SI training on students' overall listening comprehension abilities. Next, it investigated the accuracy of students' SI performance in two examinations, explaining the process and product of SI training, to clarify student problems and strategies. Student attitudes to training (i.e., active participation versus rejection) were measured through a survey.

In recent decades, several papers and books have examined various teaching methods used in university interpreting courses, focusing mainly on existing pedagogical models. Few studies, however, have empirically analyzed the possibilities and limitations of innovative interpreting programs, especially those offered to university students with no prior interpreting training. In particular, very few empirical studies have administered SI training to university students without prior CI training. This gap in the literature has served as a point of departure for the present study.

While there is a general consensus that the simultaneous mode is more complex than the consecutive mode, the sequence in which they are taught is controversial (Pöchhacker, 2016). This study has allowed students to undergo SI training directly, giving this method precedence over CI training, an approach that runs contrary to widely accepted procedures. It aims to show that students who undergo SI training directly produce acceptable target-language texts over the course of a semester. It also explores the pedagogical implications of this curricular approach in university interpreting programs.

\section{BACKGROUND}

\section{A. Basic Tenets of Interpreting and Interpreting Education}

In the last decade or so, many interpreting programs, especially graduate programs, have been established in Asia as well as in Europe to meet the growing demand for interpreters. The initial training generally involves CI, which is taught over one or two semesters, along with non-interpreting exercises, such as paraphrasing, summarizing ideas, and subsequent note-taking (Bao, 2015). In CI, note-taking is a key priority, guiding smooth interpretations by teachers and students in professional and academic arenas. Some research on CI teaching, however, has countered the well-established belief in the importance of note-taking by warning of the dangers of excessive, verbatim notation (Mead 2011; Thiéry 1981). Today, there is general agreement that the primary objective of CI is to capture the "sense" or essential meaning of language, rather than individual words (Seleskovitch \& Lederer, 1989). The major interpreting programs introduce, repeat, and reinforce these basic CI concepts and exercises before SI training begins.

To succeed at SI, interpreters must capture the sense of speech in the source language. Trainee interpreters often struggle to combine the listening and speaking components of this task. Seleskovitch and Lederer (1984) have identified three principal components of SI: comprehension, deverbalization, and expression. Gile (2009) has established an effort model for the SI process, consisting of the effort expended on listening and analysis, short-term memory, speech production, and coordination (of the resources needed to complete the three other tasks) (Gile, 2009).

\section{B. Working Memory}

From a psychological perspective, researchers have argued that WM plays a central role in SI (Christoffels, de Groot, \& Kroll, 2006; Gill, 1997). However, studies of SI expertise have reported mixed results in accurately measuring the relationship between WM capacity and performance level in SI. Padilla et al. (1995) have argued that, although an individual's WM span is a factor in successful interpreting, it does not underpin the ability to comprehend speech in the source language (SL) or produce the target language (TL), while simultaneously receiving input. Just and Carpenter (1992) have emphasized that WM performance varies, intrinsically and substantially, from individual to individual.

\section{Semantic Chunking Input}

According to Goldman-Eisler (2002), segmentation or semantic chunking of input is the key to 
comprehension in SI, in terms of semantic processing. In SI, the segmentation of speech is perceived through comprehension rather than perception; segmentation supports information processing during the act of translation. Phrased in more technical terms, input chunking, the first phase of processing, is decoded upon reception, in accordance with grammatical principles. Hence, the most economical procedure in SI appears to involve storing each decoded sequence in the active verbal memory in segments, and recoding it into the target language during the actual process of encoding (Goldman-Eisler, 2002). The present study argues that students who wish to successfully perform SI should focus on enhancing their ability to segment or semantically chunk input. During this process, they will become more aware of translation units and be able to focus more closely on what is being said, while concurrently serving as a speaker.

\section{Source Language Presentation Rate}

Given that simultaneous interpreters are highly motivated to avoid falling behind, the source-language input rate may be an important factor in achieving a successful SI performance. Gerver (2002) has investigated the effects of various source-language presentation rates on SI performance, by changing the input rate. As input rates become faster, simultaneous interpreters lag further behind and make more mistakes. From a technical perspective, Gerver argues that when total processing capacity is exceeded, interpreters are forced to pay less attention to input and output. Less material is available for recall and translation, resulting in more omissions and errors. Similarly, Fouke and Sticht (1967) have noted that the input rate has a greater effect on comprehension than the intelligibility of the text.

\section{E. Linguistic Complexity of the Source Speech}

Hild (2011) measured the accuracy of SI in relation to four parameters of linguistic difficulty: sentence density, syntactic complexity, the type of clause, and the type of subordination. She then compared professional interpreters and student interpreters, using those parameters. Her results showed that accuracy significantly deteriorated, especially among students, when participants faced these four problem triggers. In researching the ability to distinguish main from secondary ideas in SI, Liu et al. (2004) noted that experienced interpreters were able to distinguish relevant from irrelevant information, while student interpreters included main and secondary information to the same degree in their TL texts.

\section{F. Advance Preparation}

It is of primary importance to select the appropriate materials for students with no prior experience in SI, or even CI, when introducing SI training. Teachers should avoid source texts with problem triggers, such as strong foreign accents, proper names, enumerations, and high delivery rates (Gile, 1995) and select source texts that are highly intelligible and less syntactically complex. Nonetheless, even with the use of appropriate source materials, many specialists consider it audacious to administer SI training directly to untrained students, without providing CI activities in advance. To compensate for the students' lack of comprehension ability, the present experiment allowed students to see the speech script immediately before carrying out SI during the first half of the semester. There is a consensus that SI performance improves if the source speech is made available-prior topic-specific knowledge significantly aids text comprehension, processing, and related performance measures (Alexander et al., 1994; Díaz-Galaz, Padilla, and Bajo, 2015). Furthermore, familiarity with the material influences the storage of information in WM; storing lexical-semantic knowledge associated with words in long-term memory has been shown to support information processing in WM (Yudes, Macizo, \& Bajo, 2012). It is generally recognized among professional interpreters that preparing for interpreting assignments is a typical feature of professional practice (Diriker, 2004; Gile, 2002); it is therefore valid to allow students preparation time to consider the source speech.

Against this background, I conducted a survey to ascertain student views on SI activities. Taking their feedback into account, the present study has explored various learning outcomes and teaching methods that combined process- and product-oriented approaches to investigate the feasibility of introducing students directly to SI activities in university interpreting courses.

\section{RESEARCH QUESTIONS}

The study has attempted to answer the two research questions below:

1) Can students develop their listening comprehension abilities through SI activities in the course of a semester?

2) Can students produce acceptable target-language texts in SI, if SI training is administered directly, without following the usual process (introducing consecutive interpreting before SI training)?

\section{METHOD}

\section{A. Research Participants}

This research was conducted at a Japanese university I teach in, during the spring semester of 2018. Students 
attended English-to-Japanese interpreting lessons for three consecutive hours a week, completing a total of 15 lessons during the semester. The participants consisted of 20 students, all of whom were third- or fourth-year English majors enrolled in an introductory interpreting course. They were monolingual speakers of Japanese, none of whom had undergone prior interpreter training.

\section{B. Training Procedures for SI from L2 to L1 (English to Japanese)}

All lessons were carried out in the Computer Assisted Language Laboratory (CALL) or computer room of the university. During SI training, students underwent several stages of development before reaching an actual SI scenario. During the first half of the semester, lessons were structured around a process-oriented approach; during the second half, lessons were based on a product-oriented approach. The first part of the semester focused on processing SL texts. In the cognitive approach to language processing, SI has properties similar to shadowing and sight translation. Sabatini $(2000,2001)$ has shown that near-professional student subjects apply a meaning-oriented approach to shadowing tasks, obscuring the difference between shadowing and SI. Setton and Dawrant (2016) have argued that student interpreters should practice sight translation prior to and in preparation for SI. The present study administered shadowing and sight translation activities prior to SI training, to reduce the student inhibitions. Over time, the students were given opportunities to study the basic principles and practice of SI and to learn how to act as simultaneous interpreters in real-world scenarios.

During the second half of the semester, the course adopted a product-oriented approach. At this stage, students were no longer allowed to see the script in advance. They performed SI from the beginning of each exercise. SI task procedures were observed in the following order, using the same source text:

1) Shadowing (repeated three times)

2) Semantic chunking input

Students listened to an English source speech, one semantic chunk at a time. There was a pause after each chunk. During this pause, the students reformulated the chunk in L2 and then reformulated it into L1.

3) SI throughout the text

After all the L2 sentences were interpreted, the students performed SI throughout the SL text nonstop. This process was repeated six to eight times.

4) Professor's demonstration

The course teacher (also the researcher) demonstrated a model SI performance for the whole text, providing a technical explanation of how students should deliver SI for a specific translation unit.

5) Individual practice of SI

Referring to the professor's instructions, each student performed SI for the whole SL text nonstop, trying to deliver it without target-language (TL) delay. This was repeated several times.

6) Pair practice

Students were asked to perform SI in pairs to offer mutual help, with one student assisting another who was having trouble with a specific translation unit. The partners gave advice and commented on each other's delivery.

7) Group practice

Students were asked to form small groups of four to six. Each student acted as the simultaneous interpreter through a rotation. The purpose of this task was to give the students more opportunities to practice SI in scenarios that resembled real life, reducing student inhibitions by eliminating the professor's constant oversight. The students' performances were reviewed by their peers in the group.

8) Simulation of future scenarios

One student was selected to perform SI in front of the class. Where necessary, I commented on or corrected the student's performance.

\section{Data Collection}

To collect data, three different kinds of tests and one survey were conducted during the semester.

\begin{tabular}{|l|l|l|}
\hline Lesson 1 & TOEIC pre-test & Listening comprehension test \\
\hline Lesson 8 & Midterm examination & SI of a short speech (101 words, 153 wpm) with preparation \\
\hline Lesson 15 & TOEIC post-test & Listening comprehension test \\
\hline $\begin{array}{l}\text { Lesson 16 } \\
\text { (comprehensive } \\
\text { test period) }\end{array}$ & Final examination & $\begin{array}{l}\text { SI of a long speech (197 words, 120 wpm) with preparation } \\
\text { SI of a short speech (97 words, 161 wpm) with and without preparation }\end{array}$ \\
\cline { 2 - 3 } & Survey & Questionnaire on students'views of SI training \\
\hline
\end{tabular}

For the midterm examination, students performed SI from L2 to L1 on a short speech, with advance preparation; this exam reflected the fact that the students' SI skills were still immature at this point in the semester. They were given time to prepare, which allowed them to enhance their translation equivalence at the lexical and semantic levels, thereby producing acceptable TL texts. One or two lexical items, which were expected to be hard for the students to translate, were selected in advance and target-language equivalents were presented in the script handouts. The final examination proceeded as follows: the duration was 60 minutes. All 
performances were recorded on the students' own computers. They were recovered and copied onto a USB flash drive and then assessed by the author. The study design was approved by the university review board. Informed written consent was obtained from the students to use the above test results as data.

Final examination procedures for SI from L2 (English) to L1 (Japanese)

1) English speech script handouts were distributed to the students. They were then asked to begin preparing the English source text of a long speech, consisting of 197 words, for immediate SI performance. They were given five minutes preparation time. The source text was unknown material that they had never seen before.

2) The handouts used in 1) were recovered. The students listened to the source speech they had just prepared, and simultaneously interpreted it (all together) into the microphones attached to their headsets. Each student's individual SI performance was recorded onto his or her computer terminal.

3) The students were asked to listen to a short English speech, comprising 97 words, and to simultaneously interpret it, without preparation. The source text was unknown material.

4) The students were asked to perform SI on source materials that were not relevant to the present research, which took around 30 minutes. The source materials consisted of the interview script (211 words), a VOA news script (143 words), and other scripts, all of which had been attempted once in normal lessons during the semester. Irrelevant test items were inserted to reduce any practice effect that might have emerged between the first SI attempt in 3) and the following SI attempt in 5).

5) Script handouts of the English source text used in 3) were then distributed to the students. They were given three minutes to prepare for it.

6) The SL texts used in 5) were recovered. The students listened to the SL text they had just prepared, while simultaneously interpreting it (all together) into their microphones.

\section{Materials}

The difficulty levels of the short speeches used in the midterm and final examinations were almost equivalent in their intelligibility, syntactic complexity, vocabulary, student familiarity with source text information, total number of words, and student input rates. Both were recorded by the same speaker. The following passages are excerpts from the test items.

Midterm examination

Short speech at a farewell party

I have been very fortunate to have had this wonderful experience of meeting you and working with you. At first, I was in a nervous mood.... I should put into practice what I have learned here. I will keep in touch with you. (101 words) (Shibata, 2004)

Final examination

Short speech at a birthday party

My friends, I am really honored and surprised by the consideration you have shown me today. I was so impressed that all of you came so far to help me celebrate my birthday.... What a joy to have wonderful friends like you. (97 words) (Shibata, 2004)

Long speech about the Internet

Good afternoon. I'm very happy to be here to talk to such a wonderful audience as you. Today, I would like to talk about the Internet, which is one of the most important themes for people nowadays.... As you probably know, the Internet is said to have originated from the computer system in the Pentagon. After this system was adopted by research institutes and universities, it came to be widely used in the United States...... (197 words) (Mizuno \& Kagimura, 2005).

\section{E. Measurement}

Zwischenberger (2010) has reported on the metrics used by AIIC and other interpreting institutions to assess the quality of SI, and the assessment criteria are presented below. The most important criteria are sense consistency and logical cohesion, and the least important are correct grammar and a pleasant voice. Both professional interpreters and end users consider intonation and voice quality particularly unimportant as criteria for assessing the quality of interpretation (Kruz, 1989, 1993).

1) Content-related criteria

sense consistency with the original, logical cohesion, completeness

2) Form-related criteria

correct terminology, correct grammar, appropriate style

3) Delivery-related criteria

lively intonation, native accent, pleasant voice, synchronicity, appropriate style

As the participants in the present study were new learners, their performances were mainly assessed through content-related criteria. In terms of T-units, defined by Hunt (1965) as the "shortest grammatically allowable sentences into which writing can be split or a minimally terminable unit" (i.e., a dominant clause and its dependent clause), every detail of each translated sentence was assessed using a scoring rubric created by the author, which allocated specific points. If the translation of a specific sentence was left incomplete, it received 
no points. To ascertain the difficulty level of a specific word, a "word frequency list" from that academic area was used (http://www.wordandphrase.info/frequencyList.asp). Using this analytic protocol, the data were analyzed using an F-test and a $t$-test.

\section{RESUlTs}

\section{A. Quantitative Analysis}

To investigate the effect of SI training on students' listening comprehension ability, a simplified version of the TOEIC listening test was administered at the beginning and end of the semester.

TABLE I.

MARKS ObTAINED ON THE TOEIC Listening TEST CONDUCTED AT THE BEGINNING AND END OF THE SEMESTER

\begin{tabular}{lllll}
\hline & $\mathrm{N}$ & Mean & SD & $t$ \\
\hline Pre-test & 20 & 38.55 & 6.51 & -0.48 \\
\hline Post-test & 20 & 39.1 & 4.02 & -0.48 \\
\hline
\end{tabular}

As shown in Table I, the mean values were slightly higher for the post-tests than the pre-tests. However, the difference was not statistically significant $(p=.63)$. This suggests that the students' listening comprehension abilities did not develop markedly during the semester. Turning to the standard deviation, the post-test values were lower than the pre-test values, indicating that students' listening abilities varied less significantly and were more standardized after SI training.

Next, a comparative analysis was conducted on the marks obtained for SI from L2 to L1 for short speeches with preparation tasks between the midterm and final examinations (Table II).

TABLE II.

MARKS ObTAINED IN SIMULTANEOUS INTERPRETING FOR SHORT SPEECHES WITH PREPARATION IN THE MIDTERM AND FinAL EXAMINATIONS

\begin{tabular}{lllll}
\hline & $\mathrm{N}$ & Mean & SD & $t$ \\
\hline Midterm (101 words, $152.8 \mathrm{wpm})$ & 20 & 73.3 & 14 & -2.81 \\
\hline Final $(97$ words, $161.3 \mathrm{wpm})$ & 20 & 84.85 & 10.23 & -2.81 \\
\hline
\end{tabular}

Note: $* * p<.01$, full marks equal 100 points.

Table II shows that the mean value was higher for the final examination than for the midterm examination. The difference in the marks obtained between the two examinations was significant $(p<.01)$. This result suggests that SI training administered during the semester is effective in developing student' SI skills.

Next, the effect of the preparation tasks on SI performance was examined, by comparing SI of identical short speeches with and without preparation. The results are shown in Table III.

TABLE III.

MARKS ObTAined in Simultaneous INTERPRETING FOR SHORT SPEECHES, With AND Without PREPARATION, IN THE FinAL

\begin{tabular}{lllll} 
& \multicolumn{4}{c}{ EXAMINATION } \\
\hline No preparation & $\mathrm{N}$ & Mean & SD & $t$ \\
\hline Preparation & 20 & 65.6 & 13.1 & 7.54 \\
\hline & 20 & 84.85 & 10.23 & 7.54 \\
\end{tabular}

As shown in Table III, the difference was statistically significant $(p<.001)$ for SI with and without preparation. This finding suggests that, if students can process the source text immediately before the actual performance, their accuracy improves to a remarkable degree.

Next, the effect of the presentation rate and length of source speech on SI was examined. There were 197 words to interpret in long speech (120.6 wpm). 


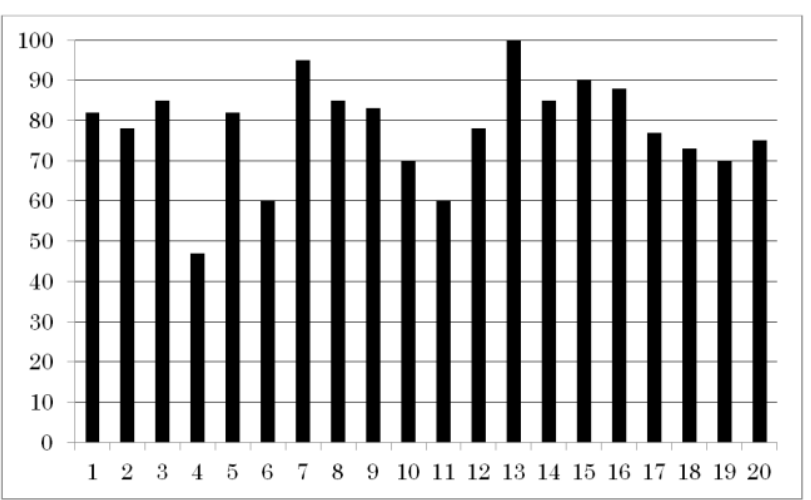

Figure 1. Comparison of students' final examination results for simultaneously interpreting the long speech, with preparation $(\mathrm{n}=20)$. Note: full marks equal 100 points.

Figure 1 shows that most students achieved relatively high accuracy (mean value $=78.15$ ). However, as indicated by the relatively high standard deviation value $(\mathrm{SD}=12.55)$, students' SI abilities varied greatly. Nevertheless, it is worth noting that most students performed extremely well, even when the source speech was long.

\section{B. Qualitative Analysis}

On the midterm examination, even though students were allowed to see the source text for three minutes before their performance, they still found it difficult to fully interpret all of the sentences in the given time. Most students omitted the same sentence, which followed another sentence with a complex syntactic structure and dense information.

"I thought it would be hard to live and work/in a place completely new and different. But everybody has been very nice and helpful."

In interpreting the first sentence, many students retained the underlined section in memory and waited for a chance to reformulate it when the whole sentence was finished; this pattern introduced omissions, errors, and departures from the translation into their renditions. Some students struggled to instantaneously decide which chunk to render first (as soon as they heard it), despite having undergone repeated segmentation and chunking input practice. However, other students were able to put what they had learned into practice and render the underlined section first.

When the ear-voice span (EVS) (i.e., latency in SI to measure cognitive processing) increases in length and accumulates until the amount of input to be stored exceeds the interpreter's storage capacity, the interpreter must catch up with the input to reduce the distance between target and source to a manageable level (Goldman-Eisler, 2002). The student interpreters found it difficult to reduce the distance. They also struggled to precisely enumerate and translate lists of items, such as living and working, new and different, and nice and helpful. Most of the students omitted the next sentence to catch up with the input and successfully interpret the sentence that followed it.

In the final examination, where the longer speech was narrated at a slower speed (120 wpm) than the short speech $(161 \mathrm{wpm})$, the students still showed target-language delay when they reached the latter half of the source speech, which included dense information.

"As you probably know, the Internet is said to have originated from the computer system in the Pentagon. After this system was adopted by research institutes and universities, it came to be widely used in the United States."

Some students found it difficult to translate "originated from," "Pentagon," and "research institute and universities." They gradually accumulated a time lag after finishing the translation of these sentences.

There is a salient difference in syntactic structure between English and Japanese-Japanese puts the verb last, while English puts it first-which causes TL delays to naturally occur. As the students were total beginners at interpreting, I suggested that they deliver concise reformulations, using simple words, to leave enough listening and processing capacity for the next incoming segment. They did not always succeed in performing the simpler reformulations and instead attempted verbatim translations, which produced more TL delays, resulting in the omission of the translation units that followed. Consequently, quality deteriorated; the students were unable to interpret the whole text in the given timeframe, leaving the last subordinate clause untranslated. Problem triggers, such as numbers- “one hundred million people," for example-were accurately translated by two-thirds of the students.

\section{DISCUSSION}

\section{A. Testing Research Question 1) Can Students Develop Their Listening Comprehension Abilities through SI}




\section{Activities in the Course of a Semester?}

An analysis of the students' pre- and post-TOEIC listening tests showed no significant development in their listening abilities, suggesting that SI training may not directly enhance listening skills, possibly because of the differences between mechanisms for processing TOEIC listening and SI. During SI, the students tried not to delay TL production; they were only a few words behind the speaker's voice, paying attention to what was being said and storing it in their short-term memories. In the TOEIC test, however, they had to store the information they had acquired through listening for a longer period of time. Specifically, while performing SI, they appeared to forget the rendition of a particular sentence immediately after its delivery ended, whereas in the TOEIC test, they needed to remember the information until they finished answering the questions presented later, a different process from SI processing.

B. Testing Research Question 2) Can Students Produce Acceptable Target-language Texts in SI, if SI Training Is Administered Directly, without Following the Usual Process (Introducing Consecutive Interpreting before SI Training)?

\section{SI of a Short Speech with Preparation}

The present study began by comparing students' simultaneous interpretations of short speeches with preparation in the midterm and final examinations. The findings showed an appreciable difference between the two examinations $(p<.01)$. Notwithstanding the higher input rate on the final examination (161.3 wpm) compared to the midterm $(152.83 \mathrm{wpm})$, the students demonstrated markedly better SI skills in the final. As already noted, Gerver (2002) investigated the effects of presentation rate by systematically expanding it from $95 \mathrm{wpm}$ to $164 \mathrm{wpm}$, and found that faster input rates caused interpreters to lag further behind and make more mistakes. It is generally recognized that, to ensure SI quality, a rate of 100-120 English words per minute is optimal for speeches that are not read from a written text, although this figure varies for other types of speech (Seleskovitch, 1978).

In the present study, the input rate was quite high during the final examination. Nevertheless, the students performed relatively well, with an $84.85 \%$ accuracy rate. They appeared to listen more carefully, taking more pauses and speaking in shorter bursts with a faster utterance speed. Their information-handling systems worked well despite the high input rate. In technical terms, when they coped with the overload induced by the high input rate, their attention was effectively shared within the system. It was divided among the input message, the processes involved in translating a previous message, and the monitoring of feedback from the present output. This may only have been possible when they saw the scripts in advance. Advance preparation may have enabled them to balance comprehension and production, arguably among the greatest sources of difficulty in SI (Christofel \& de Groot, 2005; Díaz-Galaz, Padilla, \& Bajo, 2015).

After completing a semester of SI training, the students may have adjusted to the SI environment. They seemed able to interpret more comfortably in a simultaneous mode when they'd had a chance to prepare the source text in advance. Since linguistic and semantic anticipation were easily realized, they paraphrased using more precise sentences, and occasionally voiced ideas and information in the target speech when the speaker had not verbally expressed them yet. They obtained marks of 84.85 points on average on the final examination. Although statistical evaluation - defining an acceptable accuracy rate for SI-has long been seen as irrelevant and inapplicable to an interpreter's relative and subjective performance, an accuracy rate of almost $85 \%$ can be considered a relatively good performance in simultaneous-mode interpretation.

\section{SI of a Short Speech without Preparation}

The students also attempted the same short source text without preparation. When they could not see the script in advance and had to simultaneously interpret it, during a single hearing, the students' sense consistency, logical cohesion, and completeness deteriorated. They seemed unable to anticipate from the context what would be said next or to extract the necessary information through effective attention sharing. Some became shy or soft-spoken and seemed to feel rushed. They skipped words and garbled names and places, inducing longer time lags and lower accuracy. These problems resulted in a lower mean value of 65.85 points. Seen from a more positive perspective, however, these total beginners simultaneously interpreted an unknown speech at a single hearing without any preparation and acquired as many as 65.85 points on average. As mentioned previously, there are no agreed accuracy rates for SI. However, an accuracy rate of $66 \%$ must be considered reasonably good for untrained student interpreters.

Access to source materials may be the most important factor for improving student processing and performance. Under professional conditions, interpreters are perfectly justified in asking for access to conference materials, including speech scripts or summaries, to prepare for assignments. For this reason, access to the source text is valid in initial SI training; it represents a likely scenario for possible future SI assignments.

\section{SI of a Long Speech with Preparation}

To examine the effect of source-speech length, this study also compared SIs of long speeches (197 words) with those of short speeches ( 97 words), both with advance preparation tasks. Although the presentation rate of 
the long speech was slower $(120 \mathrm{wpm})$ than that of the short speech $(161 \mathrm{wpm})$, student scores were lower for the long speech. Even though a high rate of delivery is generally viewed as a problem trigger in SI, the students performed SI less accurately with the lower presentation rate. Of course, speed is not the only problem trigger. Students also struggle with input density, the presence of numbers in the source speech, complex syntactic structures, and speakers' accents (Gile, 1995). These conditions, however, were almost identical between the two speeches, apart from numbers, which were found only in the long speech.

We can therefore infer that differences in the length of the source speeches may have influenced performance quality. More specifically, whenever a semantic chunk was unclear, the student would attempt to remember it until it became easy to understand. By that time, however, the student was storing more than one semantic chunk in short-term memory and hesitated over which chunk, the previous or the current one, should be rendered first. In the longer speech, this processing problem occurred more frequently, eventually overloading the students' processing capacity. Some managed to reduce their lags by translating in short bursts. Others were unable to recover from the TL delay and accumulated more lags, causing errors and omissions. In fact, many students failed to complete their simultaneous interpretations in the given timeframe (i.e., they were three or four words behind the source speech). For these students, synchronicity may have affected performance quality, especially when the source speech was long and time lags gradually accumulated. For some students, these time lags may have produced additional psycho-affective factors, such as anxiety or stress during longer performances. Despite this, some students performed SI extremely well under these conditions, with accuracy rates of $90 \%-100 \%$, while others fell below $60 \%$ (see Figure 1), producing a high standard-deviation value (12.55). In fact, this value was significantly higher than the SD value of 4.02 in the TOEIC post-test. Since intrinsic WM performance varies by individual (Just \& Carpenter, 1992), individual differences in WM capacity are likely to be more obvious during an SI performance than a TOEIC listening test.

\section{Qualitative Assessment}

Finally, survey questionnaires in Japanese were distributed to all of the students after the final examination was completed. The survey included six tick-box questions and one open-ended question about the SI training. In answering the tick-box questions, the students were asked to choose from the following options: Completely agree, partially agree, neither agree nor disagree, disagree partially, or disagree completely. When questioned about the effectiveness of the SI training method used in the course-which involved paired and group practice with peer review, as well as a solo SI presentation in front of the class -9 completely agreed and 10 partially agreed that the training method was effective, while 1 neither agreed nor disagreed. Asked whether the difficulty level of the SI task was appropriate, 4 agreed and 12 partially agreed that it was, while 4 neither agreed nor disagreed.

The open-ended question asked students what they thought of the SI training overall. Surprisingly, most students had a positive view. Initially, they had believed that SI was extremely difficult and nearly impossible for new learners to perform. After the SI exercises, however, they gradually learned to chunk sequential semantic input and output and were no longer bothered by the significant syntactic differences between English and Japanese. During this process, they increased their self-efficacy and belief that they could succeed at SI in a given time. Finally, they realized that they could perform SI accurately if the source speech was not semantically or syntactically difficult, and they had some time for advance preparation. Most of the students were surprised to find that they were able to perform far better than they had expected. They enjoyed the sense of accomplishment they obtained from the course. No negative views about the SI training were expressed in the open-ended question, apart from a couple of comments about the level of concentration required during the SI tasks, something they had not experienced before, which produced a great deal of stress and anxiety. Nevertheless, these students added that they enjoyed performing SI, despite their intense anxiety, and wanted to keep practicing it for possible use in the future.

\section{Interpreting Education}

SI is a real-time combination of structurally similar tasks: language comprehension and language production. It is very difficult to execute these two tasks simultaneously because they draw on the same mental resources and consequently interfere with each other (Seeber, 2015; Wickens, 2002). The research participants in this study appeared to adapt themselves to the SI environment, learning to carry out the concurrent tasks of listening and speaking in a short period of time much faster than expected. They obtained significantly higher scores in the final examination than they had in the midterm examination.

In CI, interpreters use systematic note-taking to support memory and retention when interpreting lengthy passages. It takes a significant amount of time and effort for new learners to acquire this skill. As note-taking reduces the processing capacity available for listening (Gile 2009), it may impede listening and analysis, especially during the first phase of consecutive interpreting training (Mead 2011; Thiéry 1981). In fact, I have seen many new learners give up on note-taking because it is too difficult to recover meaning from a highly fragmented notated text. Ultimately, these learners give up on CI altogether. During SI training, a similar group 
of learners translated L2 speech segments lineally, in the order they heard them, without being distracted by syntactic structure or retention. They were spared the problems of note-taking and appeared to become more committed to listening and comprehension as a result. It is likely that the students can be taught target-language fluency more effectively through SI training instead of CI training.

When it comes to the interpreter-training curriculum, the sequence in which CI and SI should be taught is controversial. The findings of this study have shown that even students new to interpreting can deliver acceptable target texts in SI, provided certain conditions are met. This finding suggests that students should be trained first in SI, rather than CI, an approach that contravenes the conventional teaching sequence. To maximize the effectiveness of interpreting practice and to enhance students' retention and memory abilities, it might be advantageous to administer CI training in the semester after SI training is completed.

The relative effectiveness of different curricular arrangements can be difficult to assess, as many aspects of teaching do not appear in the "official curriculum" (Pöchhacker, 2016). Sawyer (2004) has emphasized that researchers need access to the "hidden curriculum" experienced by individual students and teachers. The present study set out to meet that need, conducting empirical research and investigating curricular and didactic practices to explore new curricular arrangements. Admittedly, it was challenging for the untrained student participants to master the concurrent comprehension and production required for SI. There is significant scope for further research into the potential interpretation skills of non-bilingual student interpreters. However, this study offers empirical verification of the results of introducing SI activities to inexperienced students in a university interpreting course.

\section{CONCLUSION}

The present study has attempted to explore the methodological potential of introducing SI training directly to new interpreting learners at a university. Given the unique attributes of this topic, little empirical work has previously been undertaken in academia. The findings of this study indicate that students can perform SI relatively well, without having received substantial prior CI training. Clearly, further research is needed to ascertain how much SI training students should have before they begin CI training in university interpreting courses. There are also several unresolved issues, such as directionality in SI, the relevance of language-specific factors, the role of advance visual input, and various psycho-affective factors (e.g., motivation, anxiety, stress, and physical presence).

However, though its findings are inconclusive, this study provides insight into current curricular arrangements in interpreting programs. While the students who took this course were not necessarily aiming to become professional interpreters, they were all preparing for possible future SI performances. The trial-and-error process provided by this SI activity may have encouraged these students to pursue careers in interpreting, thus helping to meet the demand for skilled linguists. The success of this course also sheds light on the act of SI, introducing new pathways for developing students' linguistic skills.

\section{REFERENCES}

[1] AIIC. (no date). What is a conference interpreter? https://aiic.net/page/1403 (accessed 8/9/2018).

[2] Alexander, P., Kulikowich, J., \& Schulz, S. (1994). The influence of topic knowledge, domain knowledge and interest on the comprehension of science exposition. Leaning and Individual Differences, 6(4), 379-397.

[3] Bao, C. (2015). Pedagogy. In H. Mikkelson \& R. Jourdenais (Eds.), The Routledge handbook of interpreting. London: Routledge, 400-416.

[4] Christoffels, I., \& de Groot, A. M. B. (2005). Simultaneous interpreting: A cognitive perspective. In J. Kroll \& A. M. B. de Groot (Eds.), Handbook of bilingualism: Psycholinguistic approaches (pp. 454-479). New York: Oxford University Press.

[5] Christoffels, I., de Groot, A. M. B., \& Kroll, J. (2006). Memory and language skills in simultaneous interpreting. The role of expertise and language proficiency. Journal of Memory and Language, 54, 324-345.

[6] Díaz-Galaz, S., Padilla, P., \& Bajo, M. (2015). The role of advance preparation in simultaneous interpreting. Interpreting, 17(1), 1-25.

[7] Diriker, F. (2004). De-/Re-contextualizing conference interpreting: Interpreters in the ivory tower? Amsterdam: John Benjamins. doi:10.1075/btl.53.

[8] Fouke, E., \& Sticht, T. G. (1967). A review of research on time compressed speech. In Proceedings of the Louisville Conference on Time Compressed Speech. Louisville, Kentucky: University of Louisville.

[9] Gerver, D. (2002). The effects of source language presentation rate on the performance of simultaneous conference interpreters. In F. Pöchhacker \& M. Shlesinger (Eds.), The Interpreting Studies Reader. London and New York: Routledge, 53-66.

[10] Gile, D. (1995). Basic concepts and models for interpreter and translator training. Philadelphia: John Benjamins .

[11] Gile, D. (1997). Conference interpreting as a cognitive management problem. In H. J. Danks, G. M. Shreve, S. B. Fountain, \& M. K. Mcbeath (Eds.), Cognitive process in translation and interpreting. Thousand Oaks, CA: Sage. 196-214.

[12] Gile, D. (2002). The interpreter's preparation for technical conferences: Methodological questions in investigating the topic. Conference Interpretation and Translation, 4(2), 7-27. 
[13] Gile, D. (2009). Basic concepts and models for interpreter and translator training. Amsterdam: John Benjamins.

[14] Goldman-Eisler, F. (2002). Segmentation of input, simultaneous translation. In F. Pöchhacker \& M. Shlesinger (Eds.), The interpreting studies reader. London and New York: Routledge, 69-76.

[15] Hild, A. (2011). Effects of linguistic complexity on expert processing during simultaneous interpreting. In C. Alvstad, A. Hild, \& E. Tiselius (Eds.), Method and strategies of process research: Integrative approaches in translation studies. Amsterdam: John Benjamins, 249-267. doi:10.1075/btl/94.19hil.

[16] Hunt, K. (1965). Grammatical structures written at three grade levels. In NCTE Research report No. 3. Urbana, IL: NCTE, 1-156.

[17] Ito, H. (2017). Theory and practice of note-taking, cognitive-psychological perspective. In Y. Someya (Eds.), Consecutive Notetaking and Interpreter Training. London: Routledge, 29-70.

[18] Just, M. A., \& Carpenter, P. (1992). A capacity theory of comprehension: Individual differences in working memory. Psychological Review, 99(1), 122-149.

[19] Komatsu, T. (2017). A brief history of interpreting and interpreter training in Japan since the 1960s. In Y. Someya (Eds.), Consecutive Notetaking and Interpreter Training. London: Routledge, 5-28

[20] Köpke, B., \& Nespoulous, J. L. (2006). Working memory performance in expert and novice interpreters. Interpreting, $8,1-23$.

[21] Köpke, B., \& Signorelli, T. M. (2012). Methodological aspects of working memory assessment in simultaneous interpreters. International Journal of Bilingualism, 16(2), 183-97.

[22] Kurz, I. (1989). Conference interpreting user expectations. In D. Hamond (Ed.), Coming of Age. Proceedings of the $30^{\text {th }}$ Conference of the ATA. Medford, NJ: Learned Information, 143-148.

[23] Kurz, I. (1993). Conference interpretation: Expectations of different user groups. The Interpreters' Newsletter, 5, $13-21$.

[24] Liu, M., Schallert, D. L., \& Carroll, P. J. (2004). Working memory and expertise in simultaneous interpreting. Interpreting, 6(1), 19-42. doi:10.1075/intp.6.1.04liu.

[25] Mead, P. (2011). Co-ordinating delivery in consecutive interpreting. inTRAlinea 13. http://www.intralinea.org/archive/article/Co-ordinating_Delivery_in_Consecutive_Interpreting (accessed 17/5/2018).

[26] Mizuno, K., \& Kagimura, K. (2005). Tsuyaku jissenn toreiningu (Let's Interpret). Osaka, Japan: Osaka Kyoiku Tosho.

[27] Padilla, P., Bajo, M. T., Cańas, J. J., \& Padilla, F. (1995). Cognitive process of memory in simultaneous interpretation. In J. Tommola (Ed.), Topics in interpreting research. Turku: University of Turku, Centre for Translation and Interpreting, 61-71.

[28] Pöchhacker, F. (2016). Introducing interpreting studies ( $2^{\text {nd }}$ Ed.). London: Routledge.

[29] Savatini, E. (2000/2001). Listening comprehension, shadowing and simultaneous interpretation of two non-standard English speeches. Interpreting, 5(1), 25-48.

[30] Sawyer, D. B. (2004). Fundamental aspects of interpreter education: Curriculum and assessment. Amsterdam: John Benjamins.

[31] Seeber, K. (2015). Simultaneous interpreting. In H. Mikkelson \& R. Jourdenais (Eds.), The Routledge handbook of Interpreting. London and New York: Routledge, 79-95.

[32] Seleskovitch, D. (1978). Interpreting for international conferences. Washington, DC: Pen \& Booth.

[33] Seleskovitch, D., \& Lederer, M. (1984). Interpreter pour traduíre. Paris: Didier Erudition.

[34] Seleskovitch, D., \& Lederer, M. (1989). Pédagogie raisonnée de l'interprétation. Paris/Brussels: Didier Érudition/OPOCE.

[35] Setton, R. \& Dawrant, A. (2016). Conference interpreting: A complete course. Amsterdam: John Benjamins.

[36] Shibata, V. (2004). Hajimeteno uisuparingu doji tsuuyaku (Beginner's simultaneous interpretation by whispering). Tokyo: Nanunndou.

[37] Thiéry, C. (1981). L'enseignement de la prise de notes en interprétation consécutive: Un faux problème? In J. Delisle (Ed.), L'Enseignement de la Traduction et de l'Interprétation. De la Théorie à la Pédagogie. Ottawa: Éditions de l'Université d'Ottawa, 99-112.

[38] Tiselius, E., \& Jenset, G. B. (2011). Process and product in simultaneous interpreting: What they tell us about experience and expertise. In C. Alvstad, A. Hild \& E. Tiselius (Eds.), Method and strategies of process research. Amsterdam: John Benjamins, 269-300.

[39] Wickens, C. (2002). Multiple resources and performance prediction. Theoretical Issues in Ergonomics Science, 3(2), 159-177.

[40] Yudes, C., Macizo, P., \& Bajo, T. (2012). Coordinating comprehension and production in simult aneous interpreters: Evidence from the articulatory suppression effect. Bilingualism: Language and Cognition, 15(2), 329-339.

[41] Zwischenberger, C. (2010). Quality criteria in simultaneous interpreting: An international vs. a national view. https://www.openstarts.units.it/bitstream/10077/4754/1/ZwischenbergerFoxIN15.pdf (accessed 17/9/2018).

Hiroko Yamada is an associate professor at the University of Foreign Language, Kansaigaidai College, Japan. She obtained her master's degree at Ritsumeikan University, and is registered in a doctoral course at the Graduate School of Kyoto University. She is interested in interpreting pedagogy, and has a great deal of experiences in consecutive and simultaneous interpreting. 